\title{
On the English Translation of Li Bai's "Six Poems of Border Tune" (No. 1) under the "Three-Level Poetry Translation Criteria"
}

\section{Feng Tingting, Wang Feng*}

\author{
School of Foreign Studies, Yangtze University, Hubei, 434023, PRC China \\ *Corresponding Author
}

\begin{abstract}
Tang poetry, a treasure of Chinese historical and cultural heritage, represents the highest level of classical Chinese poetry. As one of the famous representatives of Tang poetry, Li Bai's poetry has great poetic and aesthetic value. The translation of Li Bai's poetry catches much importance amid the "Chinese culture going global" and cultural self-confidence. This article takes Dr. Wang Feng's "Three-Level Poetry Translation Criteria" as the theoretical basis, and analyses six English translations of Li Bai's "Six Poems of Border Tune" (No. 1). Based on these analyses, the authors aim to demonstrate that the theory is reasonable and feasible, which provides references and suggestions for the translation studies of Li Bai's poetry in the future.
\end{abstract}

Keywords-Three-Level Poetry Translation Criteria, English Translation of Li Bai's poetry, Six Poems of Border Tune (No. 1)

\section{INTRODUCTION}

During the Tang Dynasty (618-907) when the economy and culture reached its peak, a large number of famous poets emerged amid the prosperity of economy and culture, such as Li Bai, Du Fu and Bai Juyi. With its rich form, wide range of subjects and unique artistic charm, Tang poetry represents the highest level of classical Chinese poetry. As one of the famous representatives of the Tang poetry, Li Bai's poetry has great poetic and aesthetic value. The translation of Li Bai's poetry has significant meaning amid the "Chinese culture going global" and cultural self-confidence. Taking Dr. Wang Feng's “Three-Level Poetry Translation Criteria" as the theoretical basis, the article analyses six English translations of Li Bai's "Six Poems of Border Tune" (No. 1) by Zhao Yanchun, Sun Dayu, Xu Zhongjie, Charles Budd, Tang Zichang and W.J.B. Fletcher. Based on these analyses, the authors aim to demonstrate that the theory is reasonable and feasible as a principle of poetry translation practice and criticism in promoting the further dissemination of classical Chinese poetry.
At the beginning of the $20^{\text {th }}$ century, the English translation of Li Bai's poems has entered a new era. Many famous foreign translators began to translate his poems. There were two kinds of guidelines when they translate poems. One group of poets advocated translating Li Bai's poems into free verse style, such as Pound, Waley, Bynner, Lowell and Ayscough; while the other group including Giles and Fletcher insisted that Li Bai's poems should be translated into metrical poems.

There are also many Chinese scholars who are keen on the English translation of Li Bai's poems at home, such as Weng Xianliang, Lin Yutang, Xu Zhongjie, Sun Dayu and $\mathrm{Xu}$ Yuanchong. Also there are many famous theories guiding poetry translation, such as Lin Yutang's "Five Beauties Theory", Xu Yuanchong's "Three Beauties Theory" and Gu Zhengkun's "Five Images Theory". Bases on these theories, Dr. Wang Feng proposed the "Three-Level Poetry Translation Criteria", which provided a comprehensive guideline for poetry translation, including the "Harmony" theory at the macro level, the "Similarity of Styles, Senses and Poetic Conceptions" at the middle level, 
and the "Eight Beauties" at the micro level (Wang Feng, 2015:144-162).

\section{II. "SIX POEMS OF BORDER TUNE" (NO. 1) AND ITS ENGLISH VERSIONS}

\section{1 "Six Poems of Border Tune" (No. 1)}

"Six Poems of Border Tune" (No. 1) is one of the unique masterpieces of Li Bai (701-762). This series of poems were written in 743 , the first year Li Bai came to Chang'an. At that time, he hoped to spare no efforts to make contributions to his country. The original poem is as follows:

塞下曲六首·其一
唐代: 李白
五月天山雪, 无花只有寒。
笛中闻折柳, 春色未曾看。
晓战随金鼓, 宵眠抱玉鞍。
愿将腰下剑, 直为斩楼兰。

The first line means that it is still full of snow in the Tianshan Mountain in the fifth month, and there is only cold wind without any flowers. The second line means that the poet hears someone playing "The Plucking of Willow" with a flute, thinking that his hometown is full of spring, but he hasn't seen any trace of spring here. The third line means soldiers fight bravely with the enemies by the sound of war drums in the day, and sleep with saddles in hands at night. The last line means the poet hopes to kill the enemies in Loulan to settle the border as soon as possible and to make contributions to the country.

\subsection{English Versions of Li Bai's "Six Poems of Border Tune" (No. 1)}

The authors collected six English translations of $\mathrm{Li}$ Bai's "Six Poems of Border Tune" (No. 1) both from China and the West: Zhao Yanchun (version 1); Sun Dayu (version 2); Xu Zhongjie (version 3); Charles Budd (version 4); Tang Zichang (version 5) and W.J.B Fletcher (version 6).

\section{Version 1:}

Six Poems of Border Tune (No. 1)

The fifth moon, Mt. Heavens in snow, No flowers seen anywhere but cold.

Willow Twig's heard from a flute blow,

Although no spring one can behold.
The soldiers fight, by war drums raised;

At night, holding saddles they sleep.

I'd take off my sword from my waist,

And all Lowland's Huns I would sweep.

(Tr. by Zhao Yanchun)

\section{Version 2:}

In June* on Mount Tian-shan there's naught but snow;

No flowers could be seen, still tarrieth the cold.

Mid tunes of flutes is heard The Plucking of Willow,

The vernal hues of Spring are yet to behold.

The battles at dawn ensure from drums and gongs,

In nocturnal slumbers I doze off in saddle-hugging,

I would this flashing sword here by my loin,

Be thrust forth straight for the foe Lou-lan's head-cutting.

- The word in the original text is "May", according to the

Chinese lunar calendar; "June in the English version is so translated according to the Gregorian calendar. - Ed.

(Tr. by Sun Dayu)

\section{Version 3:}

A frontier song (No. 1)

O'er Tienshan is snow even in April.

Only boundless wastes; no flowers appear.

Amidst the flute's trilling notes, willows snap.

One never sees the colors of spring here.

At morn, men fight where the drum directs them.

At night, on their saddles, they sleep astride.

Ready, with the swords hanging on their waists,

To thrust through and capture Loulan with pride.

(Tr. by Xu Zhongjie )

\section{Version 4:}

The Tien-shan peaks still glisten,

In robes of spotless white;

To songs of Spring I listen,

But see no flowers around.

The ground is bare and dreary,

No voice of Spring I hear,

Save the "Willow Song"; so eerie,

I play upon my flute.

At morn the fight will follow,

The sound of bugle call;

Each man, in sleep, the hollow,

Across his saddle clasps.

And by his side unrusted, 
His sword is closely laid,

With which he long has trusted,

The tyrant foes to slay.

(Tr. by Charles Budd)

\section{Version 5:}

FRONTIER SONG

Li Bai

Snow is on Tienshan* till the Fifth Month,

There are no flowers, only coldness.

I hear flute melody of Picking Willows,

Yet I do not see any Spring color.

I follow drums into morning fighting;

And I hold silver saddle while sleeping.

I hope the sword hanging on my waist

Is simply to kill invading Lurlans*.

Tienshan, the Heaven Mountains.

Lurlans were western tribes.

(Tr. by Tang Zi-chang)

\section{Version 6:}

\section{ON THE FRONTIER}

'Tis June -- and still on Altai there lies the bitter snow. Amid the chill of winter no happy flowers grow.

Although the wailing flute may sing "The Willow of the Spring,"

The colour of the vernal leaves this place can never know. The kettledrum at daylight calls forth to war's array. In midnight sleep our saddles we dare not put away. This cursed tyrant Lou-lan who us to death would bring, With this good blade within my belt how gladly would I slay!

Note: -- Lou Lan who had made himself hated for his cruelty was assassinated when drunk by three men.

(Tr. by W.J.B. Fletcher)

\section{A COMPARATIVE ANALYSIS OF THE} ENGLISH TRANSLATION OF LI BAI'S "SIX

\section{POEMS OF BORDER TUNE" (NO. 1) UNDER THE} "THREE-LEVEL POETRY TRANSLATION

\section{CRITERIA"}

\subsection{Analysis at the Macro Level}

At the macro level, drawing on the basic theory of Chinese Confucianism, Dr. Wang takes "Harmony" as the macro standard of poetry translation. There are six disharmonies based on the differences between Chinese and English, including the artistic vs. scientific, lyrical vs. narrative, change in tones vs. stress in syllables, parataxis vs. hypotaxis, suggestiveness vs. decorativeness, and uniformity vs. enjambment. Based on these disharmonies, Dr. Wang put forward the "Harmony" theory at the macro level.

In Li Bai's "Six Poems of Border Tune" (No. 1), the first three lines all write about the hardships of frontier life. But the last line express the poet's ambition to make contributions to his country. The poetic line “愿将腰下剑, 直为斩楼兰" reflects the poet's firm determination to make contributions to his country. Though quite different in wording from the original, expressions such as "Be thrust forth straight for the foe Lou-lan's head-cutting" in version 2 and "To thrust through and capture Loulan with pride" in version 3 respectively express the poet's ambition to kill the enemies for his country.

\subsection{Analysis at the Middle Level}

The theory of "Harmony" can only guide poetry translation practice and poetry criticism at the macro level. Therefore, it is necessary to put forward the theory of "Similarity of Styles, Senses and Poetic Conceptions" at the middle level. Every poem has its own unique style, which reflects the poet's creative ideas and artistic expressions. Translators should choose styles, senses and poetic conceptions that resemble the original.

\subsubsection{Similarity of Styles}

"Similarity of styles" means that the style of the translation resembles that of the original. The original poem is a tune about frontier life. There is no exaggeration and gorgeous words, but using plain and concise language to express the poet's determination to protect his country. The translator should not deviate from the style of the original. Among the six translations above, version 4 and 6 failed to achieve stylistic resemblance because the redundant illustrations of the poetic imagery may make target language readers misunderstood, and they diverged far from the original simplicity.

\subsubsection{Similarity of Senses}

"Similarity of senses" means that the meaning in the translation and that in the original is similar. Chinese culture belongs to high context culture, while English 
culture belongs to low context culture. Every character in Chinese poem is well-chosen, and it contains rich feelings and meanings. With the language of passion, heroism and nature, the original poem expresses the poet's heroic spirit of defending the country in the army. The English translation must resemble the original sense. Among the six translations above, all translations are similar to the sense of the original. But version 3 by $\mathrm{Xu}$ Zhongjie may have some misunderstandings when he translated “五月” as “April”. In fact, “五月” refers to the fifth month in the lunar calendar, and it cannot be translated into April.

\subsubsection{Similarity of Poetic Conceptions}

"Similarity of poetic conceptions" means that the comprehensive effect of the poetic conception produced by the translations in the target readers' mind should be similar to that of the original poem in the mind of the original readers. The "Border Tune" is a tune about the hardships of frontier life. Among the six translations above, five of them achieved resemblance in poetic conceptions, only version 6 was translated with obvious foreign culture, and it may create different poetic conceptions in the target readers' mind.

\subsection{Analysis at the Micro Level: Eight Beauties}

Dr. Wang (2015) put forward the the "Eight Beauties" at the micro level, which is based on Xu Yuanchong's "Three Beauties Theory" -- "beauty in sense, sound and form"; Gu Zhengkun's "Five Images Theory" including "visual image, musical image, semantic image, allusive image and style image" and Lin Yutang's "Five Beauties Theory", which includes beauties in sound, sense, emotion, temperament and form. The theory of "Eight Beauties" is a more comprehensive criteria in poetry translation.

\subsubsection{Beauty of Form}

Beauty of form refers to the integral form of the poem, which is determined by the number of lines, arrangement, length, indentation, and structure of poetry. Tang poetry has a typical beauty of form--symmetry. The original poem consists of five characters in each line, it cannot be translated with a long English sentence. Chinese characters are different from English words, because one English word may have many syllables. With limited syllables, it is difficult to keep the number of lines, syllables and length corresponding with the original text and the meaning fully expressed. In that case, the beauty of form should not be overemphasized. As for the six versions above, version 1 by Zhao Yanchun has 8 syllables in each line, whereas other translations are with ten syllables approximately. Most of them consist of eight lines and reflect the beauty of form in poetry translation. But version 4 has 16 lines, which are far from the original in terms of length.

\subsubsection{Beauty of Musicality}

Beauty of musicality refers to the beauty formed by the tone and rhythm of syllables in poetry. It's important to reproduce its musical beauty in Chinese poetry by using the metrical patterns in English poetry. In the original poem, the last character of each line rhymes with "an", such as “寒 (han)”、“看(kan)”、“鞍(an)”、“兰(lan)”, which reflects the beauty of musicality. There are metrical style and free verse style in poetry translation. Version 1, 2, 4 and 6 are in the metrical style, which significantly reflects the musical aesthetics and refinement. Others use the free verse style, which results in the dearth of "beauty of musicality."

\subsubsection{Beauty of Images}

Beauty of images refers to the combination of subjective feelings and external objects. And it refers to the visual beauty formed by the perceptual elements of the vivid imagery or image group in reality or imagination. “雪” and “寒” are images about the weather, which aim to illustrate that the weather is extremely bad and reflect the hardships of frontier life. “金鼓” and “玉鞍” are images of frontier war, which reflect the stress and tension of military life. Version 4 by Charles Budd uses a metaphor in translation as in "The Tien-shan peaks still glisten in robes of spotless white", but it seems to depict a beautiful scene and cannot reflect the coldness of the weather.

\subsubsection{Beauty of Emotion}

Beauty of emotion refers to the poet's emotions through his words or subjective expressions. The purpose of the poem is to express the poet's emotion, so it is important to reproduce the emotional beauty. The first three lines all write about the hard condition of frontier life, whereas the last line express the poet's ambition to make contributions to his country. The ending of this poem is magnificent and powerful, which is inseparable from the contrast of the preceding three lines. Among these six 
translation, all of them almost express the poet's spirit and emotion, but version 4 and 6 fail to do this to a certain extent because foreign translators may feel difficult to understand the feelings of the Chinese poets due to cultural differences.

\subsubsection{Beauty of Implication}

The beauty of implication is one of the most remarkable aesthetic characteristics in Chinese poetry. The poet's emotion may be very implicative. The Tianshan Mountain is isolated and covered with snow all the year round, forming a great contrast between the inland and border area. However, the poet did not describe it in detail, but expressed it as a normal sight with "there is no flower but cold". The preceding four poetic lines illustrate a bad environment. They are natural in language and pave the way for the following lines. Among the translations above, the word "pride" could be found in Xu Zhongjie's translation, and "gladly" appeared in the translation from W.J.B. Fletcher. However, those words explicitly convey the poet's feeling; thus, the beauty of implication could be lost to a certain degree.

\subsubsection{Beauty of Diction}

The beauty of diction requires the translator to respect the hard work of the original author in the creation, so that the translation at the word level is suitable to express the content. For example, "晓(xiao)" and "宵(xiao)" have the same pronunciation in Chinese, but "晓(xiao)" means "in the morning", "宵(xiao)" refers to the "night". These two words are antithesis, enhancing the expression effect. $\mathrm{Xu}$ Zhongjie, as in Version 3, translated them into "at morn" and "at dawn", which well suit the spirit of the original with a faithful diction to some degree.

\subsubsection{Beauty of Allusion}

Allusion contains rich characteristics of Chinese traditional culture. The proper use of allusion can make poetry concise, implicit and meaningful. But it may cause difficulties in English translation. If it is necessary, we can put a note at the end of the translation. In this poem, “楼兰 (Loulan)" originated from the story of Fu Jiezi in the Western Han Dynasty. The King of Loulan (the name of the border area) was fatuous and greedy for money. Fu Jiezi was sent to the Western Region to kill the king of Loulan and to make contributions to the country. The last two lines of this poem express the patriotic passion of frontier soldiers. In these English versions, “楼兰” was translated as "Lowland", "Lou-lan", and "Lurlans". In fact, “楼兰” is an important and common image in Chinese poetry; thus, it can be translated as "Loulan" with a note with detailed information.

\subsubsection{Beauty of Gestalt}

The beauties of form, musicality, image, emotion, implication, diction, and allusion are discussed above, with other beauties not discussed in this article, which as a whole form the beauty of gestalt. The beauty of gestalt is an organized whole perceived as more than the sum of its parts. Generally speaking, Zhao Yanchun's and Sun Dayu's translations enjoy the beauty of gestalt from many aspects.

\section{A TRANSLATION FROM THE CO-AUTHORS}

Inspired by the comprehensive analysis of the translations from different scholars and Dr. Wang Feng's "Three-Level Poetry Translation Criteria," the co-authors also have a translation below:

Six Poems of Border Tune (No. 1)

$$
\text { Li Bai（李白） }
$$

Tr. by Feng Tingting \& Wang Feng

In fifth moon, Mt. Tianshan in snow, Flowers can't be seen in the cold day. A flute plays The Plucking of Willow; There's no trace of spring in the way. At morn, by war drums soldiers fight; At dawn, holding saddles they sleep. I'd take off the sword from my waist, And all Loulan's Huns I would sweep. Notes:

折柳 (The Plucking of Willow): the name of an ancient piece of music.

楼兰 (Loulan): It alludes to the story of Fu Jiezi in the Western Han Dynasty. The King of Loulan (the name of the border area) was fatuous and greedy for money. Fu Jiezi was sent to the Western Region to kill him and make contributions to the country.

\section{CONCLUSION}

Based on the comprehensive analysis of the 
translations both from Chinese and Western scholars, we can see that their translations have both advantages and disadvantages. However, it cannot be denied that there are still misunderstandings and mistranslations in poetry translation. Also it shows that Dr. Wang Feng's "Three-Level Poetry Translation Criteria" is reasonable and feasible as a principle of poetry translation practice and criticism.

There are still a few limitations in this paper, such as the comments on these translations may be subjective, and the translation provided by the co-authors is not perfect. The authors do hope that critical perspectives and constructive suggestions could be gained for the promotion of this theory. This study hopes to provide references and constructive suggestions for the translation studies of $\mathrm{Li}$ Bai's poetry. For the development of Chinese literature translation, joint efforts should be made to promote the further dissemination of classical Chinese poetry.

\section{FUNDING}

This work was supported by the National Social Science Fund of China under Grant [Key Project 17AZD040].

\section{REFERENCES}

[1] Budd, Charles (trans.). Chinese Poems. Oxford: Oxford University Press, 1912.

[2] Fletcher, W.J.B. (trans.). Gems of Chinese Verse. Shanghai: The Commercial Press, 1919.

[3] Sun, Dayu (trans.). An Anthology of the Tang Dynasty Poetry. Shanghai: Shanghai Foreign Language Education Press, 2007.

[4] Tang, Zichang (trans.). Poems of Tang. California: T. C. Press, 1969.

[5] Wang, Feng. A Comprehensive Study on the English Translation of Classical Tang Poetry. Beijing: China Social Sciences Press, 2015.

[6] Xu, Yuanchong. Li Bai and Byron. Journal of Foreign Languages, 1992(3): 30-44.

[7] Xu, Zhongjie (trans.). Two Hundred Chinese Tang Poems in English Verse. Beijing: Beijing Language Institute Press, 1990.

[8] Zhao, Yanchun. Six Poems of Border Tune (No. 1). Foreign Language Research, 2018(1): back cover. 